\title{
横型乾式ビーズミルを用いたケイ砂粉砕におけるビーズ径の効果
}

\author{
田村 崇弘 ${ }^{1 *}$, 石川 剛 ${ }^{1}$, 木俣 光正 ${ }^{2}$
}

\section{Effect of Bead Diameter on Quartz Sand Grinding Using Horizontal Dry Bead Mill}

\author{
Takahiro Tamura $^{1 *}$, Tsuyoshi Ishikawa ${ }^{1}$ and Mitsumasa Kimata ${ }^{2}$
}

Received 26 June 2020; Accepted 28 August 2020

\begin{abstract}
Grinding machines are a main force in grinding work and various types of grinding machines have been developed and used. In today's industry, where particles need to be ground down to smaller size than ever before, utilization of bead mills, a type of agitated media mill, can be an effective grinding method. On the other hand, not enough study has been made on the bead mill because it is still new in the history of the grinding machine. In this study, grinding tests were thus conducted with a dry-type bead mill, using different sizes of beads. As a result, the distribution of particle diameters changed in a similar way, regardless of the bead size, as the grinding proceeded. Further, for all bead diameters, the relationship between specific energy and median diameter followed the same rule, which demonstrated that use of smaller beads increases energy efficiency in relative terms.
\end{abstract}

Keywords: Powder industry, Bead mill, Dry grinding, Fine grinding.

\section{1. 緒言}

単粒子の集合体である粒子群，すなわち粉体はほとん どの場合，構成する粒子の大きさおよび形状に分布を有 しており，たとえば, 同様の砕料であってもこれらの状 態により流動性や圧縮性など，粉体がもつ性質が異なる ことは身近な経験からも認識することができる。多くの 産業では粉体が持つ性質に着目し，製品開発に利用され ることが一般的であり，したがって，粉体に関する研究 対象も多岐にわたる。粉砕は端的には前述した粉体その ものを得るための単位操作であることから，その重要性 を認識することは比較的容易であるが，これを研究対象 とした場合, 粉体の様相を変化させる動的過程として捉 える必要性が生じるため, きわめて複雑な系となる。ま た，多くの場合粉砕を行う手段として粉砕機が用いられ るため, 粉砕機と粉砕現象を合わせた研究が行われ報告 されている $[1,2]$ 。現在では粉砕機も多種にわたり開発さ れ $[3,4]$, 粉体を構成する粒子径もミリオーダーからミク ロンオーダー, さらに近年ではナノオーダーへと進歩し

\footnotetext{
1 アシザワ・ファインテック株式会社 微粒子技術研究所 （テ323-0034 栃木県小山市神鳥谷 2-1-4）

Institute of Powder Technology from Ashizawa Finetech Ltd.

(2-1-4 Hitotonoya, Oyama, Tochigi 323-0034, Japan)

2 山形大学大学院理工学研究科物質化学工学専攻 ( ₹ 992-8510 山形県米沢市城南 4-3-16)

Department of Chemistry and Chemical Engineering, Graduate School of Science and Engineering, Yamagata University

(4-3-16 Jonan, Yonezawa, Yamagata 992-8510, Japan)

* Corresponding Author t-tamura@ashizawa.com
}

ている。多種多様な粉砕機の中でも特にミクロンオーダー からナノオーダーの粉体生成に優位性を示す粉砕機に ビーズミルが挙げられる。これは媒体攪挥型といわれる 粉砕機の一種で, 分野によって媒体攪挥型ボールミルと も呼ばれる。具体的にはアジテータの回転により, 高い 運動エネルギーを与えられるビーズ（媒体）を介して, 高確率の下で粒子に対し, 衝突やせん断, 摩擦などの作 用を複合的におよぼす粉砕機構によるところが大きい。 さらに, ビーズミルでは変速機を用いてアジテータ周速 (回転数) を変化させることが一般的であるため, ビーズ に与えるエネルギーに幅を持たせることができる。した がって, 運転範囲が広く, 粉砕機や解砕機としての用途 以外にもメカノケミカル反応を利用した複合化処理など の応用分野への活用にも期待が持てる。また, ビーズミ ルはほかの粉砕機に比べ高い生産能力を有しており, こ れは産業の観点において生産面積削減に有効であるとい える。一方で, ボールミルをはじめとするほかの粉砕機 に比べ普及率が低いというのも事実である。これにはさ まざまな要因があり得るが, その一つにビーズミルに対 する認知度の低さが考えられる。実際, これまでの報告 をみてもビーズミルを用いた研究は挙げられてはいるも のの[5,6], ほかの粉砕機を用いた研究報告 $[7,8]$ に比べき わめてすくない。特にビーズミルを気相中での粉砕, す なわち乾式粉砕に利用した報告はほぼなれていないと いえる。しかしながら, 乾式粉砕においても前述したビー ズミルの利点や特徵を有し, さらに超微粉砕が可能とな れば, 産業界に大きく貢献すると考えられる。以上のこ 
とから筆者らは乾式のビーズミルに着目し, 以前に数種 の碳料を用いて粉砕実験[9]を行った。その結果, 乾式 ビーズミルに扔けるさらなる微細化および効率のよい粉 砕を実現するためには, ビーズミルに使用する材質やビー ズ径, 用いる粉砕助剤や気体の違いから生じる粉砕䨌囲 気の変化が粉砕結果に与える影響に関して知見を得るこ とが重要であると考えられた。その中で，ビーズ径につ いては神田らは単粒子破壊の観点から, 田中らは集合粉 砕の観点から考察し[10,11], 特に小径ビーズを用いた粉 砕の有用性に関してそれぞれ言及をしている。以上のこ とから本報では粉砕実験を行い，使用するビーズ径の違 いが粉砕にて到達する粒子径や粉砕のエネルギー効率に 与える影響を検討した。その際, 使用するビーズ径によっ て到達する粒子径や粉砕のエネルギー効率が明らかに変 化し，小径ビーズの使用が有用であることが確認できた ので報告を行うものとした。

\section{2. 実験方法}

\section{1 実験装置}

本実験に用いた粉砕装置の概略および実験フローを Fig. 1 (a), (b) に機械仕様を Table 1 にそれぞれ示した。装 置は, 乾式ビーズミル上部に定量フィーダを備えた連続 パス運転方式であり, 定量フィーダにはスクリューフィー ダ（アキュレートフィーダ 302, クマエンジニアリング 製）を, 乾式ビーズミルには粉砕室容量 $4.0 \mathrm{dm}^{3}$ の砕料 投入部に粉砕助剂投入口を備えた横型粉砕機（ドライス ターSDA5，アシザワ・ファインテック製）を用い，砕 成物はロードセルを備えた容器で回収された。本粉砕装 置において，原料となる供給粒子（砕料）は定量フィー ダにて粉砕室内に粉砕助剂とともに供給されると, 粉砕 室内部に備え付けられたアジテータの回転により運動を 与えられた粉砕メディア (ビーズ, YTZ，ニッカトー製） が砾料と接触し，この間に生じる衝撃と摩擦により粉砕 が進行する。その後, 出口付近に設置されたスクリーン によりメディアと粉砕された砕料が分離され排出される
Table 1 Machine conditions

\begin{tabular}{ll}
\hline Machine & SDA5 \\
\hline Vessel volume & $4.0 \mathrm{dm}^{3}$ \\
Vessel material & Stainless steel (SUS304) \\
Agitator material & Tool steel (SKD) \\
Beads material & Partially stabilized zirconium oxide (PSZ) \\
\hline
\end{tabular}

Table 2 Grinding conditions

\begin{tabular}{ll}
\hline Bead diameter $[\mathrm{mm}]$ & $1.5,3.0,5.0$ \\
Filling of beads $[\mathrm{vol} \%]$ & $65,70,75,80$ \\
Agitator peripheral speed $[\mathrm{m} / \mathrm{s}]$ & $3,4,5,5.5,6$ \\
Feeder feed rate $[\mathrm{kg} / \mathrm{h}]$ & 5.0 \\
Grinding aid & Ethanol \\
Amount of addition $[$ mass $\%]$ & 1.0 \\
\hline
\end{tabular}

ことで砕成物が得られるという原理となっている。本実 験では定量フィーダ単体で供給質量を決定した後, ビー ズミルの運転を開始させ，その後，ビーズミルから排出 される砕成物の質量をロードセルで測定を行った。なお， 供給質量とビーズミルから排出された質量との間に変化 がなくなった点を定常運転状態とし, それ以降の砕成物 を実験データとした。得られた砕成物はレーザー回折式 粒度分布測定機（MT-3000，マイクロトラック・ベル製） を用いて測定を行い, ここから得られた情報から乾式ビー ズミルの特性に関する考察を試みた。

\section{2 実験条件}

本実験における粉砕条件の詳細を Table 2 に示した。 砕料としてメディアン径 $129.5 \mu \mathrm{m}$ の天然鉱物である東北 硅砂 8 号 (北日本産業製) を用い, ビーズミルの機械的 運転条件は, アジテータの先端速度を $3,4,5.5,6 \mathrm{~m} / \mathrm{s}$, ビーズ径を $\phi 1.5,3,5 \mathrm{~mm}$, ビーズ充填率を $65,70,75$, $80 \mathrm{vol} \%$ と変化させ，それぞれ粉砕実験を行った。また， フィーダの供給速度は $5.0 \mathrm{~kg} / \mathrm{h}$ の設定值とし, 各計算に

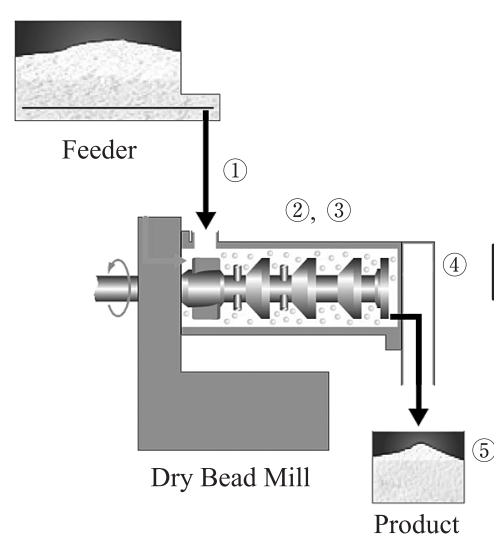

(a) Experimental apparatus

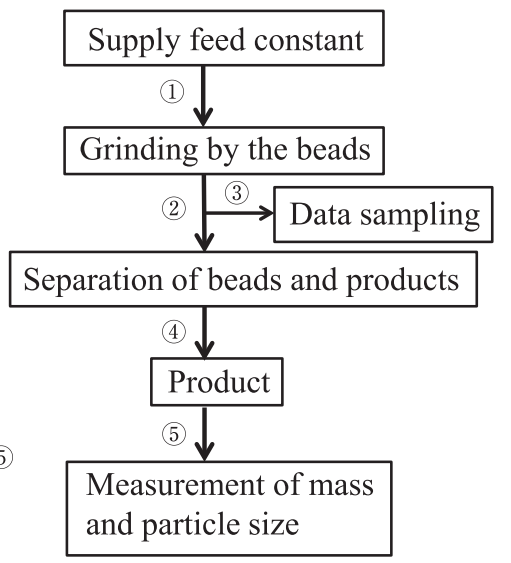

(b) Flowchart

Fig. 1 Experimental method with dry bead mill (a) Experimental apparatus (b) Flowchart 
Table 3 Minimum particle sizes of $D_{10}, D_{50}$ and $D_{90}$

\begin{tabular}{cccc}
\hline & $\phi 5 \mathrm{~mm}$ & $\phi 3 \mathrm{~mm}$ & $\phi 1.5 \mathrm{~mm}$ \\
\hline$D_{10}[\mu \mathrm{m}]$ & 0.90 & 0.76 & 0.65 \\
$D_{50}[\mu \mathrm{m}]$ & 3.37 & 2.28 & 1.63 \\
$D_{90}[\mu \mathrm{m}]$ & 10.6 & 6.39 & 3.82 \\
\hline
\end{tabular}

は実測値を用いた。砕成物の粉砕室内への付着を防止す る[12,13]ために, フィーダ供給質量に対し 1.0 mass $\%$ の タノールを粉砕助剤として用いた。

\section{3. 結果および考察}

\section{1 粒子径および粒子径分布とビーズ径との関係}

粉体は得られる粒子径や粒子径分布の形により, 流動 性や充填性などの粉体特性を大きく変化させるため, 得 られた粒子径と粒子径分布に関する研究も行われている [14,15]。本実験においては, Table 2 に示した実験範囲の 中で各ビーズ径において得られたもっとも小さなメディ アン径 $D_{50}$ と節下 $10 \%$ 通過径 $D_{10}$, 節下 $90 \%$ 通過径 $D_{90}$ を 到達限界粒子径とし, Table 3 にそれぞれ示した。また, 本報における通過径はいずれの場合も体積基準のものと する。Table 3 より, 到達限界径はいずれの通過径におい ても使用するビーズ径に依存しており，小さなビーズを 使用するほど，砕料が微細化されていることがわかる。 これは，同じ充填率において使用するビーズを小さくす ることで，単位時間あたりの砕料に対する衝突頻度が向 上したことに加えて，ビーズ間の空隙が狭まることで, より小さな粒子がビーズ間に拘束されるようになったた めと考元られる。次に, 各条件により得られた粒子径分 布に打ける $D_{90}$ および $D_{10}$ の比 $D_{90} / D_{10}$ とメディアン径 $D_{50}$ との関係を Fig. 2 に示した。ここで，通過径の意味から 粒子径分布をもつ砕成物の体積の内 $10 \%$ が $D_{10}$ 以下であ り，90\%が $D_{90}$ 以下である。したがって，砕成物全体の $80 \%$ の粒子は $D_{10}$ と $D_{90}$ との間の粒子径をとるため, いい 換えれば, 粒子径比 $D_{90} / D_{10}$ は 1 に近いほど得られた砕成 物内の粒子径分布幅が狭いということになる。Fig. 2 に おいて $\phi 3 \mathrm{~mm}$ のビーズ径を用いた場合をみると, 粒子 径比 $D_{90} / D_{10}$ は, $D_{50}$ が $3.5 \mu \mathrm{m}$ 以上ではほぼ一定の值を示 すが，それ以下では $D_{50}$ が小さくなるにしたがい粒子径 比 $D_{90} / D_{10}$ も小さくなることが確認できる。そこで同ビー ズを使用した際の実験により得られた粒子径積算分布を Fig. 3 に示した。ここで, 図の破線は本実験に用いた砕 料の粉碎前粒子径積算分を示し, 実線は周速, ビーズ充 填率をおのおの変更して粉砕実験を行った際に得られた ものであり, 図の左にある積算分布ほどより大きなエネ ルギーを機械から与えられている。このときの機械的仕 事量を Table 4 に示した。Fig. 3 から粒子径分布は形状を 変えずに推移するが $D_{50}$ が $3.5 \mu \mathrm{m}$ 以下になると微小粒子 側の粉砕が進行しなくなり，しだいに粒子径分布幅は狭 くなる。したがって $D_{90} / D_{10}$ の值が小さくなることから Fig. 2 で確認された結果が生じたと考えられる。この要

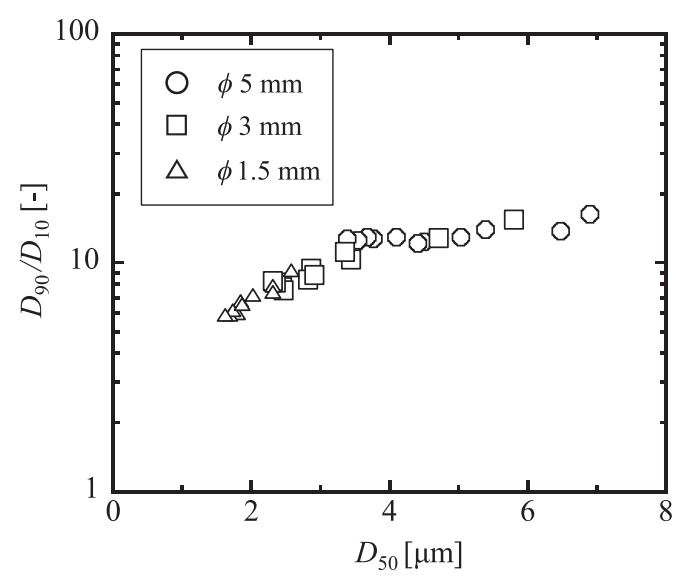

Fig. 2 Relationship between $D_{50}$ and $D_{90} / D_{10}$

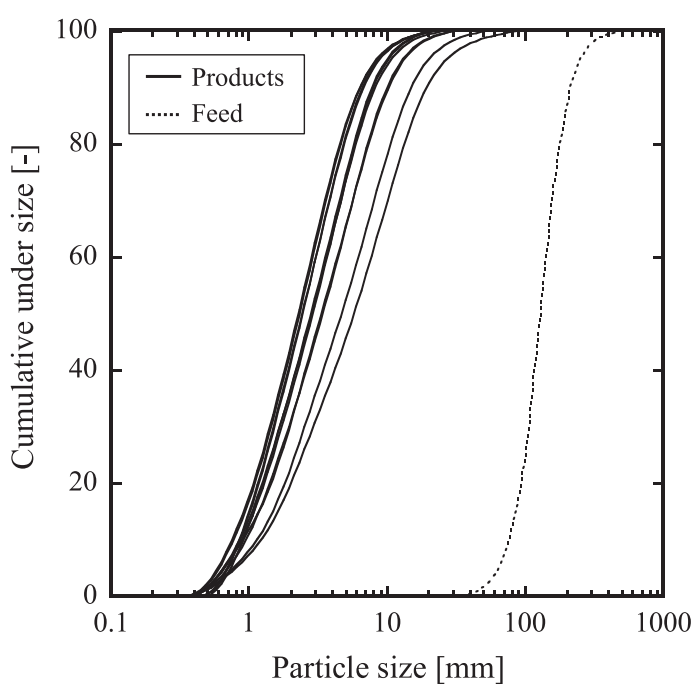

Fig. 3 Particle size distribution at $\phi 3 \mathrm{~mm}$ bead

Table 4 Grinding conditions and Specific energies at $\phi 3 \mathrm{~mm}$ bead

\begin{tabular}{ccc}
\hline $\begin{array}{r}\text { Specific Energy } \\
{[\mathrm{kJ} / \mathrm{g}]}\end{array}$ & $\begin{array}{r}\text { Agitator peripheral } \\
\text { speed }[\mathrm{m} / \mathrm{s}]\end{array}$ & $\begin{array}{c}\text { Filling of beads } \\
{[-]}\end{array}$ \\
\hline 0.44 & 3 & 70 \\
0.57 & 3 & 75 \\
0.85 & 4 & 65 \\
0.85 & 3 & 80 \\
1.14 & 4 & 70 \\
1.25 & 4 & 75 \\
1.37 & 4 & 80 \\
1.62 & 5 & 65 \\
1.92 & 5 & 70 \\
2.18 & 5 & 75 \\
2.74 & 5 & 80 \\
\hline
\end{tabular}

因が砕料や本実験で用いた粉砕機の条件とどのように関 係しているかは不明であるが，おそらく，微細化により 微小粒子は塑性変形[16]や凝集現象を生じることで粉砕 確率の著しい低下を招いていると考えられる。 


\section{2 使用ビーズ径と粉砕のエネルギー効率}

目標とする粒子径を有した砕成物を生産する際，時間 あたりの生産能力およびその機械的仕事量は, 粉砕操作 を必要とする産業において粉砕機の占有面積の削減や生 成コスト削減に直結する重要な要素である。このため, 粉砕機の性能を評価する際には前者を生産能力, 後者を 粉砕のエネルギー効率という形で表し，これら二つを指 標にすることが多い。一方で, 粉砕機を用いた粉砕操作 では年間に膨大な量のエネルギーが費やされているが, そのほとんどが熱に変わってしまい実質的に粉砕に使用 されるエネルギーは大きくても $5 \%$ 程度, 小さい場合に は $1 \%$ 未満であるといわれている[17]。加えて, 近年の環 境問題への配慮からエネルギー削隇の動きが高まってい ることからも，本報では任意の粒子径に着目した場合の エネルギー効率と使用ビーズ径との関係について検討す ることとした。そこで, 着目粒子径には代表径として用 いられることが多いメディアン径 $D_{50}$ を採用し，これと 次式 Eq. (1)にて求めた砕料単位質量あたりに与えられる 機械的仕事量 $E_{\mathrm{p}}$ との関係を Fig. 4 に示す。ここで $E_{\mathrm{t}}$, $E_{\mathrm{n}}, W$ はそれぞれ動力計により取得した機械の全動力, 同周速においてビーズや砕料を粉砕室内に含まない際の 空動力および砕料のフィード量である。

$$
E_{\mathrm{p}}=\frac{\left(E_{\mathrm{t}}-E_{\mathrm{n}}\right)}{W}
$$

田中ら[18]は粉砕限界となる比表面積が存在し, 微小な 比表面積の変化と与えられる仕事量との比について Eq.

(2)で表される関係を示した。

$$
\frac{d S}{d E_{\mathrm{p}}}=k\left(S_{\infty}-S\right)
$$

さらに, 比表面積 $S$ とメデイアン径 $D_{50}$ との関係を Eq. (3)

$$
S=\frac{\phi}{\rho_{\mathrm{p}} D_{50}}
$$

で仮定し，これを Eq. (4)の形に整理し，ここから導出さ れる Eq. (6)の理論曲線を Fig. 4 内に実線で示した。

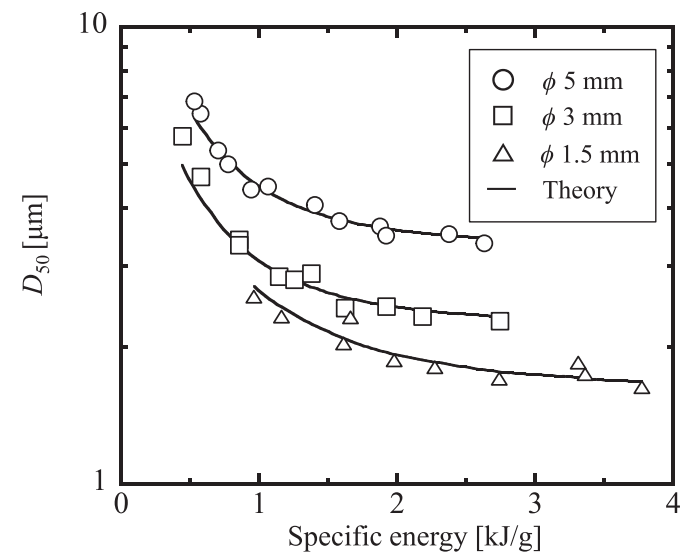

Fig. 4 Relationship between the specific energy and $D_{50}$ in each bead size
Table 5 Parameter obtained in grinding

\begin{tabular}{cccc}
\hline & $\phi 5 \mathrm{~mm}$ & $\phi 3 \mathrm{~mm}$ & $\phi 1.5 \mathrm{~mm}$ \\
\hline$k$ & 1.37 & 1.34 & 0.950 \\
\hline
\end{tabular}

$$
\begin{aligned}
& \frac{d D_{50}}{d E_{\mathrm{p}}}=-k D_{50}^{2}\left(\frac{1}{D_{\infty}}-\frac{1}{D_{50}}\right) \\
& \int_{D_{0}}^{D_{50}} D_{50}^{-2}\left(\frac{1}{D_{\infty}}-\frac{1}{D_{50}}\right)^{-1} d D_{50}=-\int_{0}^{E_{\mathrm{p}}} k d E_{\mathrm{p}} \\
& D_{50}=\frac{D_{\infty}}{1-\left(1-\frac{D_{\infty}}{D_{0}}\right) e^{-k E_{\mathrm{p}}}}
\end{aligned}
$$

ここで, $S_{\infty}, k, \rho_{\mathrm{p}}, \phi, D_{\infty}, D_{0}$ は順に限界比表面積, 粉 砕係数 [18], 粒子密度, 形状係数, 到達限界メディアン 径および初期メディアン径である。本報では粒子密度お よび形状係数は一定とし, 仕事量 $E$ には機械的仕事量 $E \mathrm{p}$ を到達限界メディアン径には Table 3 に示した值をそれぞ れ用いた。また，粉砕係数 $k$ の決定は各ビーズ径にて Eq. (6) を求め, その結果を Table 5 に示した。ここで Eq. (7)

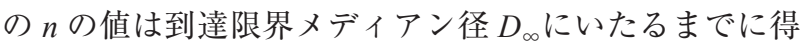
られたデー夕数である。

$$
k=\frac{1}{n} \sum_{i=1}^{n} \frac{1}{E_{\mathrm{p}_{i}}} \ln \frac{D_{50_{i}}\left(D_{0}-D_{\infty}\right)}{D_{0}\left(D_{50_{i}}-D_{\infty}\right)}
$$

Fig. 4 から使用するビーズ径に応じた Eq. (1)にて求めら れた単位質量あたりの機械的仕事量をとメディアン径と の関係はいずれのビーズ径を使用した場合においても害 測值と理論值との間で良好な一致が確認された。ここか ら単位質量あたりの機械的仕事量は各粉砕条件により変 化する值であるが, 本実験の範囲においては Eq. (4)に示 される関係で整理できることがわかる。さらに，Eq. (4) から粉砕係数が大きく到達限界メディアン径が小さいほ ど, 粉砕のエネルギー効率は向上すると考えられるが, Table 3 および Table 5 からは使用するビーズ径が小さい ほど到達限界メディアン径, 粉确係数双方の值が小さく なることが確認された。一方, Fig. 4 では小さなビーズ を用いた方が同じ機械的仕事量に対しょり小さなメディ アン径が得られていることが確認でき, 本実験に扔いて 小径ビーズを使用することで相対的に粉砕のエネルギー 効率が高められることが示された。さらに Fig. 5, Fig. 6 には代表粒子径のみを $D_{10}$ と $D_{90}$ に変更し, 前述した方 法で算出された理論值と実験值との関係をそれぞれ示す。 Fig. 5, Fig. 6 から代表粒子径に $D_{10}, D_{90}$ を用いた場合に も機械的仕事量に対し, 実測值と理論値との間には良好 な一致を確認できる。以上のことから本実験の範囲では メディアン径だけでなく $D_{10}, D_{90}$ を代表粒子径に用いた 場合に扔いても機械的仕事量との間には Eq. (4)の関係で 整理できることが示された。 


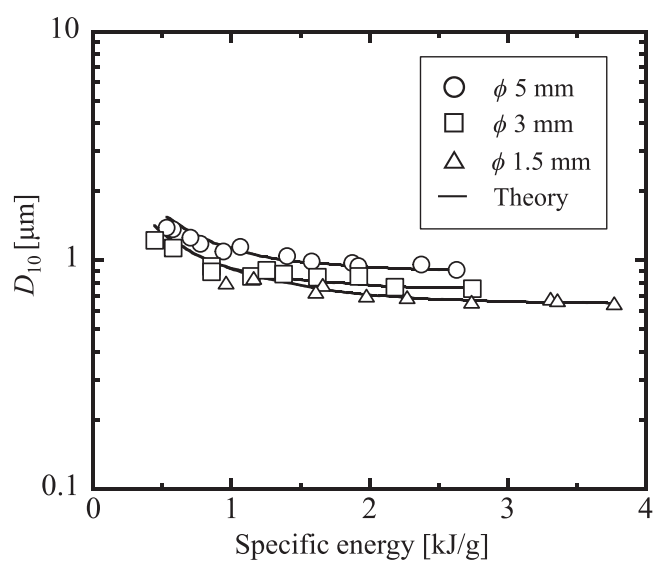

Fig. 5 Relationship between the specific energy and $D_{10}$ in each bead size

\section{4. 結言}

本報ではパス方式型の乾式ビーズミルを用いてケイ砂 粉砕実験を行い，特に使用するビーズ径の違いが粉砕に て到達する粒子径や粉砕のエネルギー効率に与える影響 を検討した。その結果得られた知見を以下に示した。

・使用するビーズ径が小さくなるにしたがいより微細な 領域へ粉砕が進行することが示された。

• $\phi 3 \mathrm{~mm}$ のビーズ径を用いた際の結果から, $D_{50}$ が $3.5 \mu \mathrm{m}$ 付近を境に $D_{90} / D_{10}$ の様相が異なることが確認された。 これは, 粒子径分布の変遷から $D_{50}$ が $3.5 \mu \mathrm{m}$ 以下で微 小粒子側の粉砕が進行せず，しだいに粒子径分布幅が

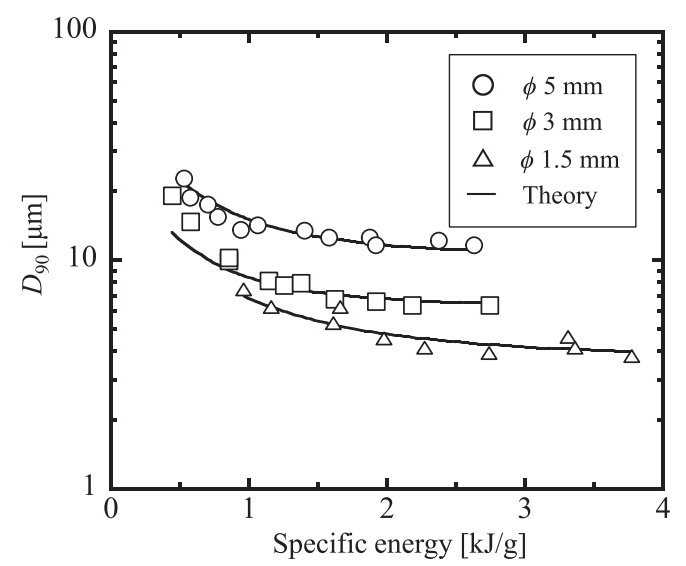

Fig. 6 Relationship between the specific energy and $D_{90}$ in each bead size

狭くなったためと考えられた。

・本実験の範囲において, 単位質量あたりの機械的仕事 量は各粉砕条件により変化する值であるが, これらと メディアン径との間はいずれのビーズ径を使用した場 合も同じ関係式を用いて整理できることがわかった。 さらに同関係式は代表粒子径に $D_{10}, D_{90}$ を用いた際に も適用できることが確認された。

・本実験において小径ビーズを使用することで，同じ機 械的仕事量に対しより小さなメディアン径が得られる ことが確認できたことから, 粉砕のエネルギー効率が 相対的に高められることが示された。
$D_{0} \quad$ : feed median size

$D_{10}: 10 \%$ in cumulative under size

$D_{50}:$ median size

$D_{90}: 90 \%$ in cumulative under size

$D_{\infty}:$ limit median size

$E_{\mathrm{n}} \quad:$ no load power

$E_{\mathrm{p}} \quad$ : specific energy

\section{Nomenclature}

$[\mu \mathrm{m}] \quad E_{\mathrm{t}} \quad:$ total driving power

[ $\mu \mathrm{m}] \quad k \quad:$ constant

$[\mu \mathrm{m}] \quad S \quad:$ specific surface area

$\left[\mathrm{m}^{2} / \mathrm{kg}\right]$

[ $\mu \mathrm{m}] \quad S_{\infty}:$ limit specific surface area

$\left[\mathrm{m}^{2} / \mathrm{kg}\right]$

$[\mu \mathrm{m}] \quad W \quad$ : feed amount

$[\mathrm{kg} / \mathrm{s}]$

$[\mathrm{kJ} / \mathrm{s}] \quad \rho_{\mathrm{p}} \quad:$ particle density

$\left[\mathrm{kg} / \mathrm{m}^{3}\right]$

$[\mathrm{kJ} / \mathrm{g}] \quad \phi \quad$ : shape factor

\section{References}

[1] T. Tanaka, Recent techniques and theories of comminution, J. Jpn. Soc. Color Materi. 52 (1979) 486-493.

[2] T. Matsuyama, Progress of powder technology, Chem. Eng. (Japan) 23 (1959) 705-709.

[3] Y. Kanda, J. Tsubaki (Ed.), Huntai no seisei, Nikkan kogyo (2005) P45.

[4] T. Matsuyama, Machin selection of mills, Chem. Eng. (Japan) 23 (1959) 723-727.

[5] T. Ishii, K. Hashimoto, The effect of grinding conditions on particle size of the ground particle obtained by using a beads mill, J. Jpn. Soc. Color Materi. 84 (2011) 163-168.

[6] T. Ishii, K. Hashimoto, Evaluation of grinding characteristics of calcium carbonate by horizontal bead mill, J. Jpn. Soc. Color Materi. 85 (2012) 53-58.
[7] Y. Kanda, H. Gunji, H. Takeuchi, K. Sasaki, Rate constants of wet and dry ball mill Grindings, J. Soc. Mater. Sci. Jpn. 27 (1976) 663-666.

[8] K. Matsui, T. Kurihara, T. Sekiguchi, Fundamental relations on the impact compressive crushing, Chem. Eng. (Japan) 34 (1970) 881-887.

[9] T. Tamura, T. Ishikawa, M. Kimata, Potentiality of fine grinding using the horizontal dry bead mill, and relationship between required power and particle size, J. Soc. Powder Technol., Japan 54 (2017) 648-653.

[10] Y. Kanda, S. Yashima, A consideration of ultrafine grinding based on fracture mechanics single particle crushing, Bull. Res. Inst. Miner. Dressin. Metall. 45 (1989) 30-38.

[11] T. Tanaka, Determining the optimum diameter of grinding 
media used for ultrafine grinding mechanisms, J. Soc. Powder Technol., Japan 31 (1994) 25-31.

[12] M. Hasegawa, M. Kimata, T. Shoji, Effect of liquid additives and behavior of alumina powder in ultrafine grinding of alumina, J. Soc. Powder Techol., Japan 39 (2002) 736-742.

[13] M. Kimata, T. Ohshima, N. Kotake, M. Hasegawa, Dry grinding of tourmaline using grinding aid of lower alcohols, J. Soc. Powder Technol., Japan 52 (2015) 10-16.

[14] M. Suzuki, A. Yagi, T. Watanabe, T. Oshima, Estimation of void fraction in a three component random mixture of spheres, Kagakukogaku Ronbunshu 10 (1984) 721-727.
[15] M. Suzuki, Y. Nakatsuji, M. Hirota, T. Oshima, Effect of size distribution on compressive property of fine powders, Kagakukogaku Ronbunshu 16 (1990) 1074-1079.

[16] L. Sikong, H. Hashimoto, S. Yashima, Size effect of breakage properties of fine single particles, Bull. Res. Inst. Miner. Dressin. Metall. 45 (1989) 23-29.

[17] G. Jimbo, Grinding operation and energy, Chem. Eng. Japan 35 (1971) 286-289.

[18] T. Tanaka, A new concept applying a final fineness value to grinding mechanism, Chem. Eng. (Japan) 18 (1954) 160171. 